\title{
Assessment of wear micromechanisms on a laser textured cemented carbide tool during abrasive-like machining by FIB/FESEM
}

\author{
Shiqi FANG ${ }^{1,2, *}$, Dirk BÄHRE ${ }^{1}$, Luis LLANES ${ }^{2}$ \\ ${ }^{1}$ Institute of Production Engineering, Saarland University, Saarbrücken 66123, Germany \\ ${ }^{2}$ CIEFMA-Department of Materials Science and Engineering, EEBE-Campus Diagonal Besòs, Universitat Politècnica de \\ Catalunya, Barcelona 08019, Spain
}

Received: 29 November 2019 / Revised: 20 March 2020 / Accepted: 07 May 2020

(c) The author(s) 2020.

\begin{abstract}
The combined use of focused ion beam (FIB) milling and field-emission scanning electron microscopy inspection (FESEM) is a unique and successful approach for assessment of near-surface phenomena at specific and selected locations. In this study, a FIB/FESEM dual-beam platform was implemented to docment and analyze the wear micromechanisms on a laser-surface textured (LST) hardmetal (HM) tool. In particular, changes in surface and microstructural integrity of the laser-sculptured pyramids (effective cutting microfeatures) were characterized after testing the LST-HM tool against a steel workpiece in a workbench designed to simulate an external honing process. It was demonstrated that: (1) laser-surface texturing does not degrade the intrinsic surface integrity and tool effectiveness of HM pyramids; and (2) there exists a correlation between the wear and loading of shaped pyramids at the local level. Hence, the enhanced performance of the laser-textured tool should consider the pyramid geometry aspects rather than the microstructure assemblage of the HM grade used, at least for attempted abrasive applications.
\end{abstract}

Keywords: focused ion beam (FIB); field-emission scanning electron microscopy inspection (FESEM); cemented carbides; laser surface texturing; abrasive machining processes; wear

\section{Introduction}

Continuous or interrupted sliding contact between hard tools and counterparts is intrinsic to all machining operations of metallic alloys. As a result, the piece gets shaped, but also the cutting tool gets worn. The amount and extensiveness of wear is the synergic result of many different factors in the tribological system, including contact and lubrication conditions as well as material properties. Reliable assessment of degradation phenomena associated with the wear of cutting tools requires both two-dimensional and three-dimensional characterization, directly linked to surface and subsurface scenarios, respectively. Cross-sectional analysis is a practical and efficient approach to revealing wear information related to subsurface integrity and microstructural changes [1-3]. Metallographic sample preparation on crosssections combined with optical and scanning electron microscopy is an inspection protocol often used for acquiring data at the subsurface level. However, the unintended (but possible) introduction of artifacts (e.g., mechanical-induced changes) during the metallographic preparation may be an important drawback. Hence, sample preparation may either affect (by hindering or even removing) wear-induced

* Corresponding author: Shiqi FANG, E-mail: shiqi.fang@uni-saarland.de 
features, such as cracks or adhered material, or introduce secondary/additional deformation and damage [1]. This additional, unintended damage is particularly present while assessing near-surface phenomena where critical features exist, especially at the surface edges of the prepared sample. Furthermore, metallographic cross-sectioning does discern general and uniformly introduced changes, but may fail to capture localized or heterogeneously distributed ones.

Following the above ideas, the use of small-scale advanced characterization techniques, such as those involving complementary actions of focused ion beam (FIB) milling and field-emission scanning electron microscopy inspection (FESEM), has emerged as a powerful tool for analyzing tribological phenomena. Unlike conventional scanning or transmission electron microscopy, a FIB-instrument employs ions, instead of electrons, as charged particles that are accelerated and focused using electric and magnetic fields. Gallium ions, generated from liquid gallium (Ga) source, are commonly used [4]. Because of the heavier character of the ions, their sputtering effect enables precise in-situ micro-milling on the target sample, i.e., at specific and selected surface locations. Meanwhile, when combined with an FESEM unit, high-spatial-resolution images can be obtained from the secondary electrons generated by ion sputtering [5-8]. Therefore, the FIB/FESEM dual-beam platform becomes a powerful tool to study concurrently induced changes, regarding surface and subsurface levels, at precise locations on the micrometer scale. Implementation of this advanced characterization technique has proven to be quite successful in characterizing degradation mechanisms of engineering materials under different service-like conditions, such as abrasive or adhesive wear $[9,10]$, corrosion [11, 12] or even tribocorrosion [13, 14]. Recently, pulsed laser emerges as a nonconventional machining approach on the micron scale, and it has been successfully implemented to functionalize the surfaces of cutting tools [15].

In high precision abrasive machining, tools are usually made from super hard materials, such as composites of diamonds or cubic boron nitrides. Such a machining process is usually expensive due to the precious materials and highly accurate control systems. In previous studies, abrasive-like microfeatures of a conventional cubic boron nitride (CBN) honing stone were successfully reproduced on a cobalt-nickel-based cemented tungsten carbide grade (WC-CoNi) using laser technique [16, 17]. The first results of the cutting tests enlightened the possibility of employing cemented carbides as an alternative to the precious materials in abrasive machining processes, as these microfeatures achieved similar material removal effectiveness as the $\mathrm{CBN}$ honing stone in the cutting tests [16]. However, mild surface degradation of these microfeatures was detected after the cutting tests. Therefore, it becomes a practical demand to access the wear mechanism of these "micro-textures" in the cutting tests with an adequate approach. To be more precise, FIB/FESEM is used in this study to assess and understand wear phenomena taking place in laser-shaped microfeatures of the hardmetal (HM) tool during the cutting test.

\section{Tools and abrasive-like testing}

The tool material was a HM grade consisting of coarse WC grains embedded in a $28.5 \mathrm{wt} \%$ metallic (CoNi) binder. Aiming to replicate topographic scenario of a conventional CBN based honing stone, a picosecond laser micromachining system sculpted arrays of hexagonal pyramids morphologically similar to abrasive grains exposing on the CBN tool surface [16]. Instead of common anisotropic geometrical properties of the diamond or CBN grains in the composites, microfeatures produced on HMs by a laser can possess geometrical regularities in order to avoid disfunction or surface damage of the diamond or CBN tools often resulting from the erupted hard grains. One of the reasons for the brutal grain eruption was the local stress concentration due to irregular geometrical properties. Figures $1(\mathrm{a}, \mathrm{b})$ and Table 1 show basic mechanical and microstructural characteristics for the laser-surface textured (LST)

Table 1 Hardness and microstructural characteristics of LST-HM tool.

\begin{tabular}{ccccc}
\hline Tool & $\begin{array}{c}\text { HV0.3 } \\
\text { (macro) }\end{array}$ & $\begin{array}{c}\text { Grain } \\
\text { quantity }\end{array}$ & Phase ratio & $\begin{array}{c}\text { Grain } \\
\text { shape }\end{array}$ \\
\hline LST-HM & 680 & 343 & $8.3 \%$ & Hexagon \\
\hline
\end{tabular}




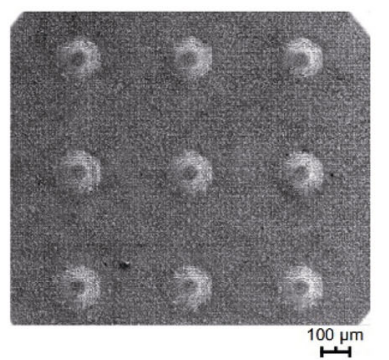

(a)

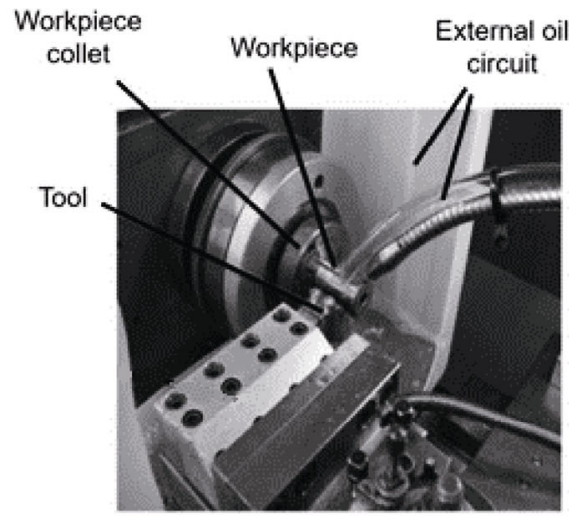

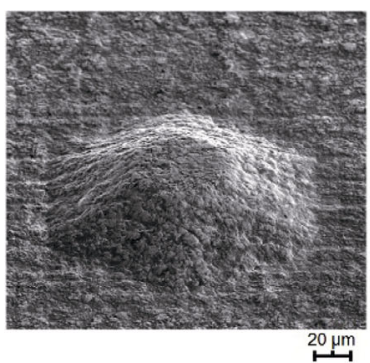

$\stackrel{20 \mu m}{\longmapsto .-1}$

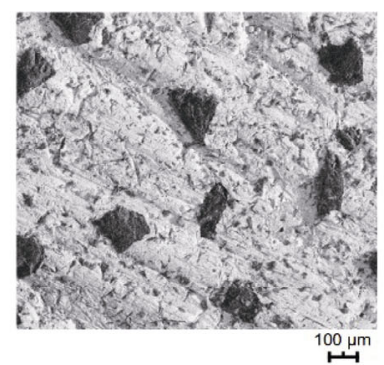

(b)

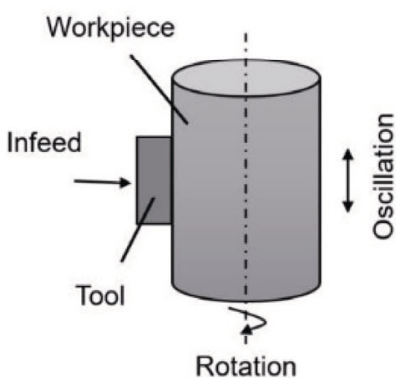

(c)

Fig. 1 (a) Laser-produced abrasive microfeatures (hexagonal pyramids) on the LST-HM tool; (b) abrasive grains exposed on a conventional $\mathrm{CBN}$-based honing stone; and (c) in-house test workbench based on the external honing process.

HM tool studied.

The cutting capability of the LST-HM tool was evaluated in a workbench designed to simulate an external honing process, under lubricated condition $[16,18]$. As illustrated in Fig. 1(c), the workbench was integrated into a lathe. In order to replicate honing, the workpiece was secured on a spindle, which could rotate at a fixed speed. Meanwhile, the test tool sample was oscillated and moved towards the workpiece through a transmission lever with a certain feed. As a result of the movements, the surface of the workpiece was machined by the honing-like action. Detailed machining parameters are listed in Table 2. In this cutting test, the workpiece was made of steel $20 \mathrm{MnCr} 5$. The working surface was preliminarily fine-turned with an arithmetic average roughness Ra about $4 \mu \mathrm{m}$. After the abrasive test, Ra came down to $0.7 \mu \mathrm{m}$. It was demonstrated that the LST-HM tool smoothed the surface of a steel workpiece, down to roughness levels close to those attained by the reference CBN honing stone.

However, morphological changes of the cutting microfeatures were assumed to be different: surface
Table 2 Machining parameters and workbench configuration.

\begin{tabular}{|c|c|c|c|c|c|}
\hline $\begin{array}{c}\text { Rotation } \\
\text { speed } \\
(\mathrm{rpm})\end{array}$ & $\begin{array}{l}\text { Oscillation } \\
\text { speed } \\
(\mathrm{mm} / \mathrm{min})\end{array}$ & $\begin{array}{l}\text { Oscillation } \\
\text { number }\end{array}$ & $\begin{array}{l}\text { Flow } \\
\text { rate } \\
\text { (bar) }\end{array}$ & $\begin{array}{c}\text { Lubricant } \\
\text { viscosity } \\
\left(\mathrm{mm}^{2} / \mathrm{s}\right)\end{array}$ & $\begin{array}{l}\text { Normal } \\
\text { force } \\
\text { (N) }\end{array}$ \\
\hline 500 & 1,000 & 20 & 0.07 & 5 & 25 \\
\hline
\end{tabular}

topography of the CBN tool retained dynamic stability due to the self-dressing phenomena, whereas the pyramids on the LST-HM tool might suffer permanent degradation. Hence, in-depth inspection and understanding of wear mechanisms of these effective cutting microfeatures on the LST-HM tool become mandatory to improve its performance.

\section{Wear-induced changes on surface and microstructural integrity of the LST-HM tool}

Following the described abrasive-like test, a direct surface inspection was carried out using FESEM (Sigma VP, Zeiss). Cutting microfeatures exhibited 
morphological changes at different levels. The most severe damage was found close to the pyramids cutting front, where penetration into the workpiece first occurred (Fig. 2(a)). At the cutting tip, large amounts of heterogeneous material were stacked, resulting in built-up edges (e.g., Fig. 2(b)) [19]. Such degradation was linked to chip adhesive wear when machining the 'sticky' material (20MnCr5), especially at the low cutting speed used in the conducted test. Around and particularly below the cutting tip, some notch wear and breakage of WC grains were also found. These phenomena should also be linked to the referred chip adhesion on the cutting tip, as it would lead to high pressure and consequent local plastic deformation at the surface. At all other sites of the pyramids, surface conditions remained almost unchanged, as sustained by the observation of the laser-induced periodic surface structures [20], e.g., Fig. 2(c). These findings

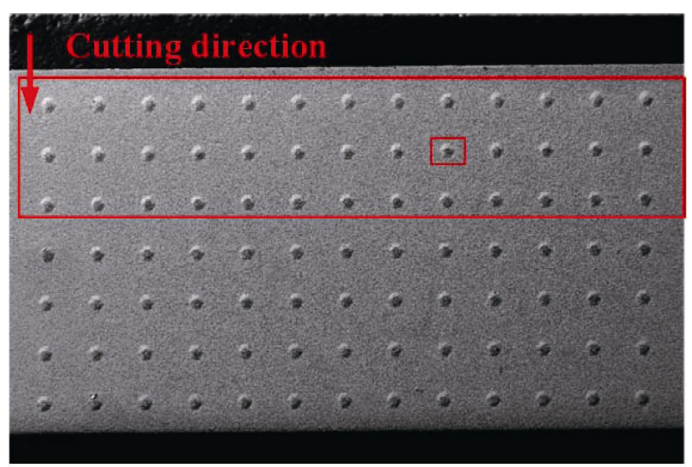

$500 \mu \mathrm{m}$

(a)

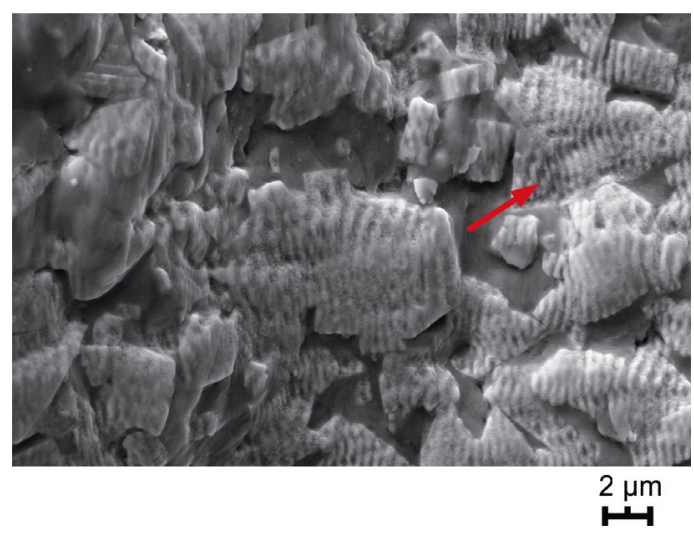

(c) were further proven by energy-dispersive X-ray spectroscopy (EDS). Several aspects may be highlighted after the resulting element distribution map (Fig. 2(d)) was analyzed. First, material removal occurred only at the top of the pyramids (effective cutting areas). Second, plenty of workpiece material (Fe) remained, due to adhesion, around the cutting tip of the pyramid. Finally, geometry and surface integrity below the top level of pyramids did not show any discernable changes. Following these microscopic observations, it may be concluded that the degradation of pyramids mainly results from sliding abrasion, rather than from abrupt breakdown or cleavage.

Cross-sectional inspections using FIB milling (Helios 600, FEI) were done at the rake surfaces of the pyramids, which are the chip flow surfaces ahead of cutting fronts (contact areas) as indicated by arrows in Figs. 3(a, c). Obviously, these places

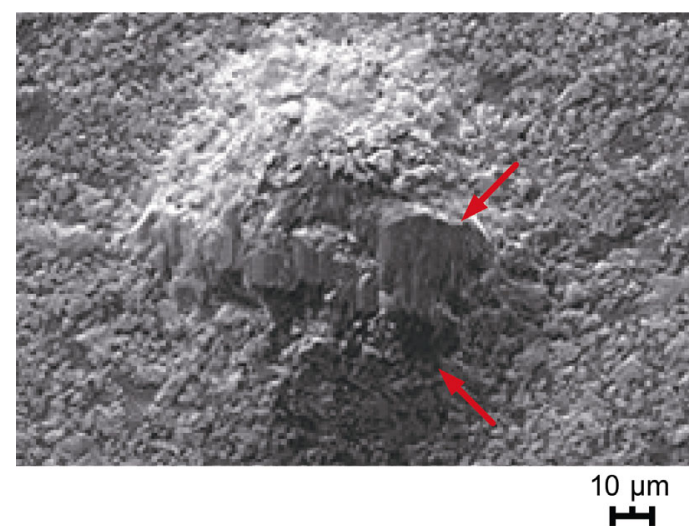

(b)

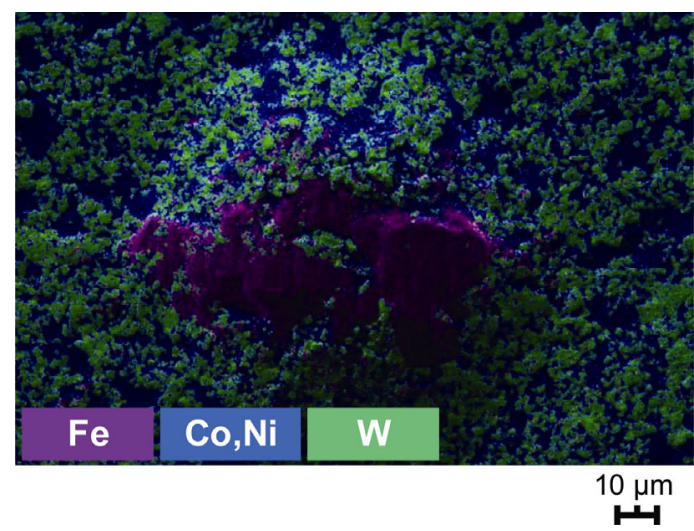

(d)

Fig. 2 Surface morphological inspection of (a) LST-HM tool and (b) one damaged pyramid with arrows indicating the adhesion; (c) partial enlargement of the area in (b) on the bottom surface with the arrow showing the intact laser induced patterns, and (d) element distribution map by EDS. 


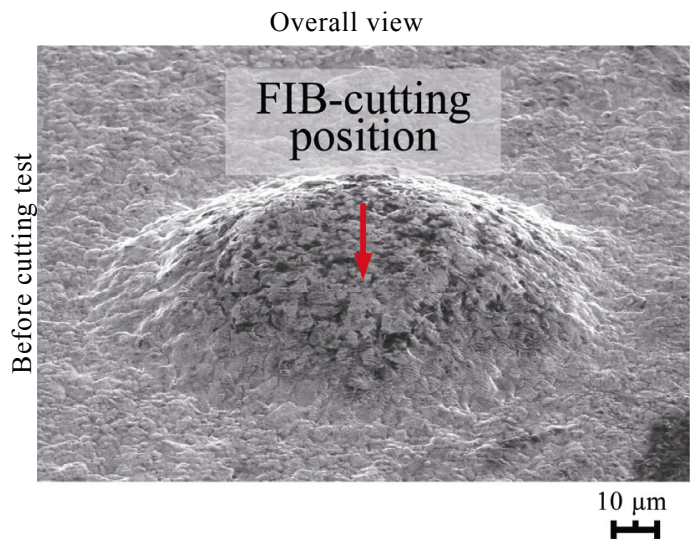

(a)

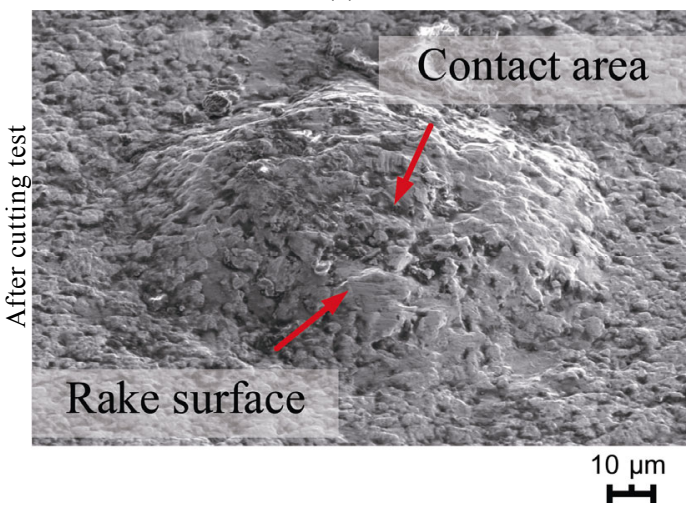

(c)

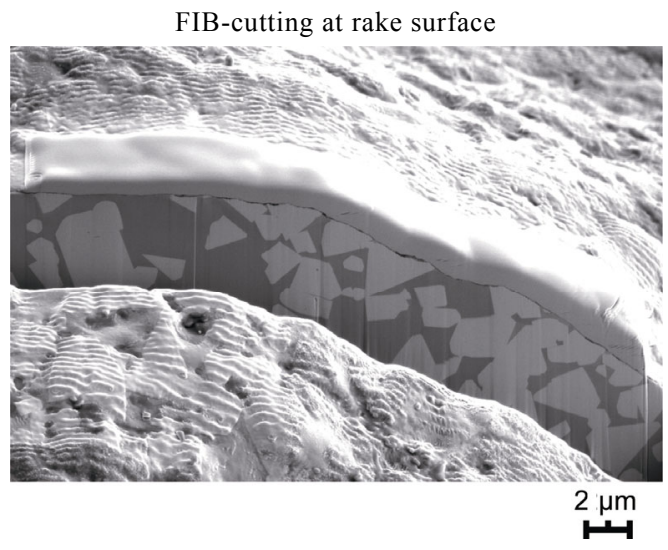

(b)

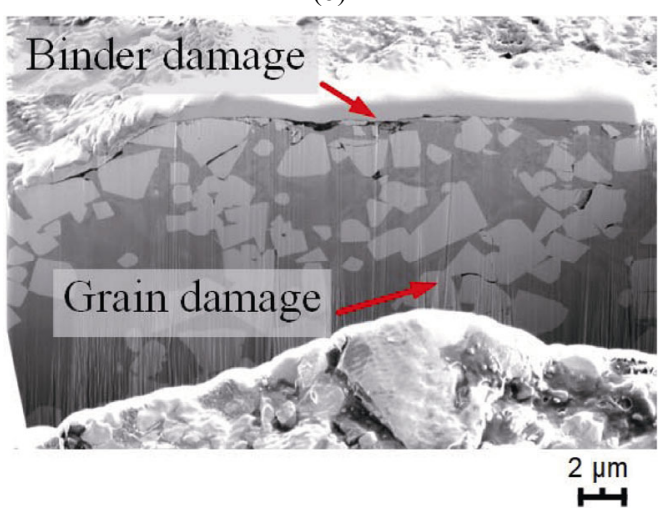

(d)

Fig. 3 FIB-cutting on the pyramid before and after the cutting tests: (a, c) overall views in terms of shape and morphology; (b, d) FIB-cuttings covering the rake surfaces and the contact areas.

are subject to damage as a result of the pressing and sliding of the chips. Analysis of a reference pyramid (i.e., before cutting test) showed a smooth profile, without evidence of any microstructural changes or damage underneath the patterned surface (Figs. $3(\mathrm{a}, \mathrm{b}))$. Corresponding subsurface images after the cutting tests are given in Figs. 3(c, d). In general, the pyramid shape was not affected, except at the position of the rake surface and cutting front. There, changes were found in both micro-constitutive phases: ceramic grains and metallic binder. As indicated by arrows in Fig. 3(d), substructural changes in the binder were concentrated on a very shallow region (about $1 \mu \mathrm{m}$ in thickness). On the other hand, damage within ceramic grains was discerned even at distances as deep as $5 \mu \mathrm{m}$.

Extensive and detailed FIB/FESEM analysis permits speculation that the wear-induced degradation of the pyramids is a sequential process resulting from pressing and sliding contact of the pyramids (abrasive units) against the workpiece during the cutting test. Different wear phenomena may be expected: deformation, cracking, adhesion, and material detachment.

At the initial stage, the tool was set to get in contact with the workpiece, followed by the application of the normal force. The penetration of the pyramids into the workpiece then occurred due to the different relative hardness between tool and workpiece. Under these indentation-like conditions, the two microconstitutive phases of the HM exhibited distinct irreversible changes. As shown in Fig. 4(a), the binder experienced plastic deformation (marked with the circle). On the other hand, cracks were discerned within the ceramic grains (indicated with the arrows), possibly as a result of strain compatibility forced by the extruded binder or from direct contact with the workpiece. In a subsequent stage, as the workpiece began to rotate, penetrating pyramids were subjected to tangential forces. As a 


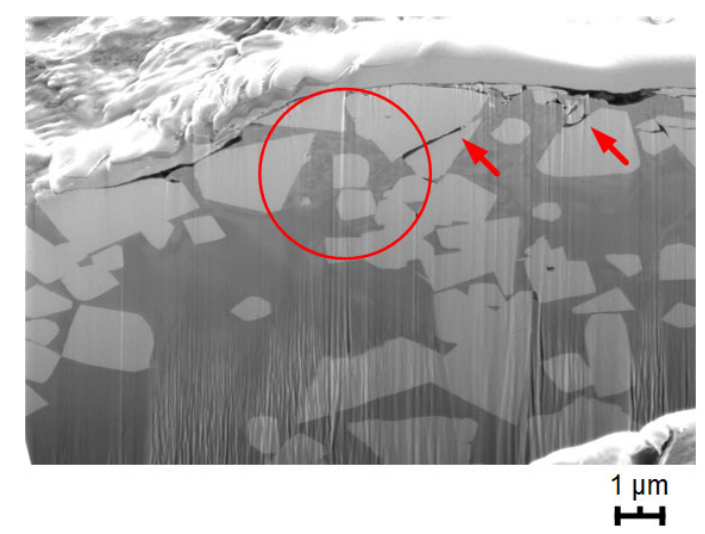

(a)

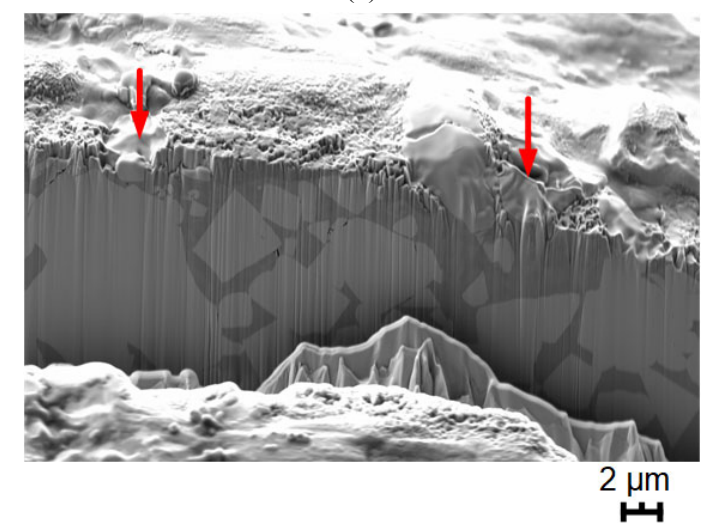

(c)

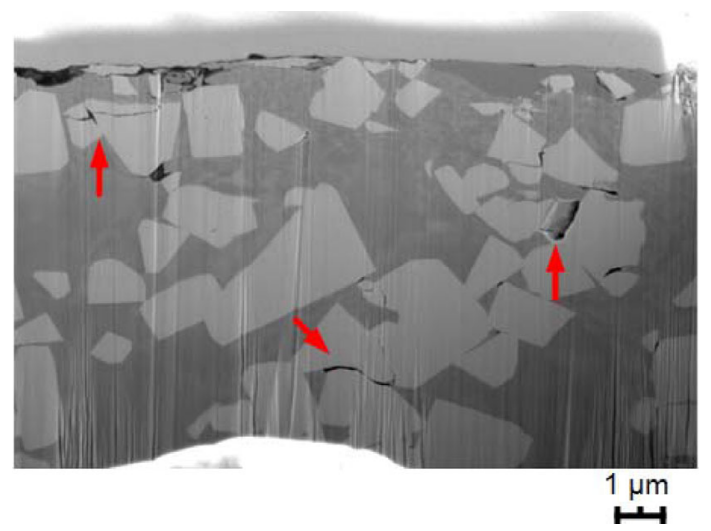

(b)

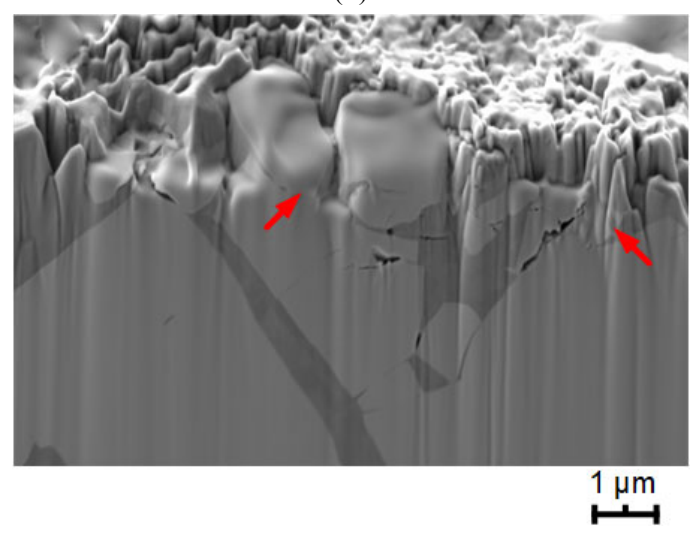

(d)

Fig. 4 Wear characterization through FIB cutting on the pyramids at the contacting area after cutting tests: (a) initiation of binder deformation and grain cracking, (b) propagation of the deformation and crushing, (c) change of tribological condition, and (d) local zoom at the surface with tribological degradation.

consequence, they undertook shear stresses, besides the normal one. The synergic effect of both stresses increased the deformation level as well as potential crack propagation. As shown in Fig. 4(b), besides damage evidenced within grains, large cracks were also found to extend along the boundaries of adjacent ceramic particles. As the rotation continued, loosed grain particles could be partially spalled or even crushed together with the adhesive binder at some places, which directly led to an uneven topography profile (Fig. 4(c)). Small-scale cavities within such profiles were then filled with workpiece material. It enhanced local adhesion, which later extended over the pyramid surface as a thin film (Fig. 4(d)). It may be expected that such a 1 micronthick layer is detrimental to the tool functionality, as the tribological condition between the abrasive pyramids and the workpiece changes. In this regard, excessive heat might be produced as galling-like friction rises, and lubrication becomes less efficient. Furthermore, the local stack of adhered material could lessen the material removal precision and increase surface roughness. The degradation of the tribological conditions led to more severe expelling or detachment of material.

Based on the FIB/FESEM characterization, it may be speculated that the vertical pressure exerted on the pyramid during the penetration was the most important factor for the harm of microstructural integrity. Afterward, shearing stress aggravated the loosening and breakdown of the grains. Besides the mechanical properties of the material, the stress resistance is also strongly related to the geometrical features of those microfeatures. Therefore, it is necessary to analyze the influence of the geometrical features on the stress distribution.

According to the initial design, pyramids with a flat (top) contact area was aimed in order to avoid 
collapse during the sliding movement (Fig. 1(a)). However, such dull cutting tips indeed translated into a rather difficult penetration. As a result, subsequent plowing into the counterpart could abruptly take place, making the workpiece suffer severe normal and shear stresses. Interaction among pyramids and the workpiece consists of many discrete area-to-area contacts during the cutting process, as a result of the smooth and flat top surface design. Therefore, local stress was hardly redistributed, and it became difficult to build up a full lubrication scenario between tool and workpiece, i.e., contacting areas rub under either mixed or even dry conditions. Such a tribological scenario aggravated the degradation of the pyramid surfaces, yielding (ceramic) grain crushing and material adhesion. Based on the above analysis, it is then suggested that a sharp penetration angle or a reduction of the contact surface area of the pyramids, especially at the positions close to the cutting tips, should be the aim for obtaining smoother penetration and plowing.

\section{Conclusions}

In this study, wear mechanisms of an LST-HM tool were characterized, after an abrasive-like cutting test. FIB/FESEM revealed the wear micromechanism of the abrasive microfeatures:

1) At the initial step, cracks appeared through the grains and along the carbide/binder interface.

2) Binder was removed layer by layer. Adhesion of workpiece material was found on the contact surface, especially at those cavities produced by the broken and erupted grains.

Based on the wear analysis, pyramid geometry, contact conditions, and material properties are recalled as critical factors to improve the tool performance: a smoother penetration and plowing should be aimed for enhancing the cutting capability of the tool. Coating of the abrasive units may also be suggested as an action towards increasing wear resistance and maintaining tribological conditions.

\section{Acknowledgements}

The work was supported by the German Research
Foundation (DFG) within the Individual Research Grant (425923019) “Laser Surface Textured Cemented Carbides for Application in Abrasive Machining Processes".

Open Access This article is licensed under a Creative Commons Attribution 4.0 International License, which permits use, sharing, adaptation, distribution and reproduction in any medium or format, as long as you give appropriate credit to the original author(s) and the source, provide a link to the Creative Commons licence, and indicate if changes were made.

The images or other third party material in this article are included in the article's Creative Commons licence, unless indicated otherwise in a credit line to the material. If material is not included in the article's Creative Commons licence and your intended use is not permitted by statutory regulation or exceeds the permitted use, you will need to obtain permission directly from the copyright holder.

To view a copy of this licence, visit http://creativecommons.org/licenses/by/4.0/.

\section{References}

[1] García J, Collado Ciprés V, Blomqvist A, Kaplan B. Cemented carbide microstructures: a review. Int $J$ Refract Met H 80: 40-68 (2019)

[2] Jacobson S, Hogmark S. Surface modifications in tribological contacts. Wear 266(3-4): 370-378 (2009)

[3] Beste U, Jacobson S. Targeting micro-sectioning-A technique to study subsurface features in worn specimens. Wear 264(11-12): 1152-1156 (2008)

[4] Escovitz W H, Fox T R, Levi-Setti R. Scanning transmission ion microscope with a field ion source. Proc Natl Acad Sci USA 72(5): 1826-1828 (1975)

[5] Volkert C A, Minor A M. Focused ion beam microscopy and micromachining. MRS Bulletin 32(5): 389-399 (2007)

[6] Kubis A J, Shiflet G J, Hull R, Dunn D N. Focused ion-beam tomography. Metall Mater Trans A 35(7): 1935-1943 (2004)

[7] Jiménez-Piqué E, Turon-Vinas M, Chen H, Trifonov T, Fair J, Tarrés E, Llanes L. Focused ion beam tomography of WC-Co cemented carbides. Int $J$ Refract Met H 67: 9-17 (2017)

[8] Velichko A, Holzapfel C, Siefers A, Schladitz K, 
Mücklich F. Unambiguous classification of complex microstructures by their three-dimensional parameters applied to graphite in cast iron. Acta Mater 56(9): 1981-1990 (2008)

[9] Rodrigues A C P, Yonamine T, Sinatora A, Azevedo C R F. Pin-on-disc tribotests with the addition of $\mathrm{Cu}$ particles as an interfacial media: Characterization of disc tribosurfaces using SEM-FIB techniques. Tribol Int 100: 351-359 (2016)

[10] Li J, Elmadagli M, Gertsman V Y, Lo J, Alpas A T. FIB and TEM characterization of subsurfaces of an Al-Si alloy (A390) subjected to sliding wear. Mater Sci Eng A 421(1-2): 317-327 (2006)

[11] King P C, Cole I S, Corrigan P A, Hughes A E, Muster T $\mathrm{H}$, Thomas S. FIB/SEM study of AA2024 corrosion under a seawater drop, part II. Corros Sci 55: 116-125 (2012)

[12] Tarragó J M, Fargas G, Isern L, Dorvlo S, Tarres E, Müller C M, Jiménez-Piqué E, Llanes L. Microstructural influence on tolerance to corrosion-induced damage in hardmetals. Mater Des 111: 36-43 (2016)

[13] Perret J, Boehm-Courjault E, Cantoni M, Mischler S, Beaudouin A, Chitty W, Vernot J-P. EBSD, SEM and FIB characterisation of subsurface deformation during tribocorrosion of stainless steel in sulphuric acid. Wear

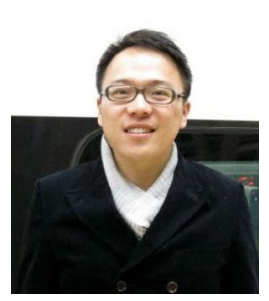

Shiqi FANG. He is a research fellow in production engineering at the Saarland University, Germany. He graduated from the University of Science and Technology Beijing, China, and the Ecole Centrale de Lyon France, and received his

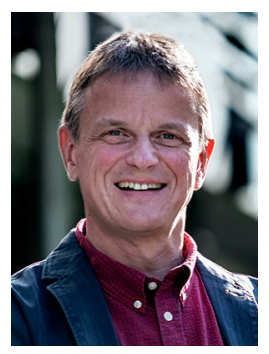

Dirk BÄHRE. He is the head of the Institute of Production Engineering, Saarland University. He studied mechanical engineering and received his Dr.-Ing. title at the Technical University of Kaiserslautern, Germany. He worked for the Robert Bosch company with responsibility for the development of manufacturing technologies. His rese-
269(5-6): 383-393 (2010)

[14] Rajahram S S, Harvey T J, Walker J C, Wang S C, Wood RJK. Investigation of erosion-corrosion mechanisms of UNS S31603 using FIB and TEM. Tribol Int 46(1): 161-173 (2012)

[15] Li H N, Axinte D. Textured grinding wheels: A review. Int J Mach Tools Manuf 109: 8-35 (2016)

[16] Fang S, Llanes L, Bähre D. Laser surface texturing of a WC-CoNi cemented carbide grade: Surface topography design for honing application. Tribol Int 122: 236-245 (2018)

[17] Fang S, Pérez V, Salán N, Baehre D, Llanes L. Surface patterning of cemented carbides by means of nanosecond laser. Mater Manuf Process 35(2): 123-129 (2020)

[18] Klein S, Fang S, Bähre D. Analysis of different surface structures of hard metal guiding stones in the honing process. Procedia Manuf 10: 265-275 (2017)

[19] Astakhov V P. The assessment of cutting tool wear. Int J Mach Tools Manuf 44(6): 637-647 (2004)

[20] Bonse J, Rosenfeld A, Krüger J. On the role of surface plasmon polaritons in the formation of laser-induced periodic surface structures upon irradiation of silicon by femtosecond-laser pulses. J Appl Phys 106: 104910 (2009)

doctorate from the Saarland University, Germany, and the Technical University of CataloniaBarcelona Tech, Spain. Dr. Fang was awarded the Erasmus Mundus fellow, Marie-Curie fellow, and Alexander von Humboldt fellow. His research mainly focuses on tool materials for high precision machining, surface engineering, and tribology.

arch foci include machining processes for high precision, tool technology, and tool innovation. He is responsible for organizing international conferences on Production Engineering such as the International Symposium on Electrochemical Machining Technology (INSECT) and International Materials Research Meeting in the greater region (IMRM). He is a member of the executive board of the European School of Materials (EUSMAT). 


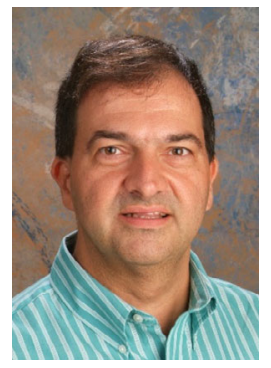

Luis LLANES. He is a full professor

His research interests include mechanical integrity in the Department of Materials Science and Engineering at the Technical University of CataloniaBarcelona Tech (UPC), Spain, and current director of UPC School of Professional and Executive Development. He received his Ph.D. degree from the University of Pennsylvania (USA). and damage assessment of hardmetals, advanced ceramics, and hard coatings. He is currently cochairman of the European Hard Materials Group (EuroHM) and shares responsibility for organizing the International Conference Series on the Science of Hard Materials (ICSHM). He is also a member of the editorial board of the International Journal of Refractory Metals and Hard Materials since 2006. 